Abstract—Results from published age and growth models for bonnetheads (Sphyrna tiburo) indicate significant differences in life history between populations in the eastern Gulf of Mexico $(\mathrm{GOM})$ and those in estuarine waters of the Atlantic coast of the southeastern United States (hereafter referred to as the Atlantic region). An age-independent model, GROTAG, was used with region-specific tag-recapture data to generate estimates of von Bertalanffy growth parameters and growth rates for sharks in each of these regions, and these estimates were compared with age-based life history characteristics. Results from the GROTAG model indicate that female bonnetheads in the GOM initially grew faster and attained a smaller maximum size than females in the Atlantic region. The final GROTAG model for females in the Atlantic region produced estimates of von Bertalanffy parameters and growth rates similar to those produced by the age-based growth model. For the population in the GOM, GROTAG model results indicate that growth rates were slower and average maximum size and longevity were greater than those from age-based models. Although models for males were generated with tag-recapture data, large 95\% confidence intervals hindered comparisons. For both sexes and regions, calculated maximum longevity and age at $50 \%$ maturity are larger than published estimates, indicating that age underestimation may have occurred in both age and growth studies, with significant differences in estimates of life history characteristics for bonnetheads in the GOM.

Manuscript submitted 1 April 2020. Manuscript accepted 9 October 2020. Fish. Bull. 118:329-345 (2020). Online publication date: 3 November 2020. doi: 10.7755/FB.118.4.3

The views and opinions expressed or implied in this article are those of the author (or authors) and do not necessarily reflect the position of the National Marine Fisheries Service, NOAA.

\section{Growth rates of bonnetheads (Sphyrna tiburo) estimated from tag-recapture data}

\author{
Bryan S. Frazier (contact author) ${ }^{1}$ \\ Dana M. Bethea ${ }^{2}$ \\ Robert E. Hueter ${ }^{3}$
}

\author{
Camilla T. McCandless ${ }^{4}$ \\ John P. Tyminski ${ }^{3}$ \\ William B. Driggers III $^{5}$
}

Email address for contact author: frazierb@dnr.sc.gov

${ }^{1}$ Marine Resources Research Institute
South Carolina Department of Natural Resources
217 Fort Johnson Road
Charleston, South Carolina 29412
${ }^{2}$ Southeast Regional Office
National Marine Fisheries Service, NOAA
26313 th Avenue South
Saint Petersburg, Florida 33701
${ }^{3}$ Center for Shark Research
Mote Marine Laboratory
1600 Ken Thompson Parkway
Sarasota, Florida 34236

${ }^{4}$ Northeast Fisheries Science Center
National Marine Fisheries Service, NOAA
28 Tarzwell Drive
Narragansett, Rhode Island 02882
${ }^{5}$ Mississippi Laboratories
Southeast Fisheries Science Center
National Marine Fisheries Service, NOAA
P.O. Drawer 1207
Pascagoula, Mississippi 39567
Growth of wild fish is primarily estimated by using 3 types of models: age-based models in which length and estimated age are known; length-based models that use modal progressions in length-frequency data; and models that use length at capture, known time at liberty, and length at recapture from tag-recapture data to model growth trajectories. Length-based models are useful; however, they are suitable only for estimating growth in younger age classes because substantial overlap in lengths of fish can occur in older cohorts (Campana, 2001; Natanson et al., 2018a). Methods based on the use of age and tag-recapture data often characterize growth of fish by using the von Bertalanffy growth function (VBGF) (Ricker, 1975; Francis, 1988a). Growth of fish is most commonly estimated by using age-based models; however, models developed with tag-recapture data are often used as alternative models for large, longlived species that may not be able to tolerate high rates of fishing mortality or for species for which age estimation is difficult or imprecise (Cailliet et al., 1992; Treble et al., 2008).

All methods of modeling growth have limitations and potential biases. Age estimation can be imprecise and is difficult to validate for many species (Beamish and McFarlane, 1983), especially elasmobranchs (Goldman, 2004) and deepwater species (Rigby et al., 2014). Validation of age estimates is recommended for all age and growth studies; however, validation of all age classes is difficult and rarely achieved (Cailliet et al., 2006). Although validation of ages has been completed for several species of elasmobranchs (Campana et al., 2002; Ardizzone et al., 2006; Kneebone et al., 2008), there is a growing body of evidence that indicates that age underestimation commonly occurs for long-lived species, such as sharks (e.g., Francis et al., 2007; Passerotti et al., 2014; Harry, 2018; Natanson et al., 2018b), as well as recent evidence that age underestimation may also occur in sharks with 
intermediate longevities (Frazier et al., 2014). For these reasons, modeling of growth with tag-recapture data and newer methods of modeling that combine tag-recapture data with age estimates have been recommended (Eveson et al., 2007; Aires-da-Silva et al., 2015; Francis et al., 2016; Natanson and Deacy, 2019).

Growth models that use tag-recapture data also have limitations and biases. To accurately represent growth in a population, recapture data should include individuals throughout the range of lengths found in the population. However, this goal is rarely achieved with most data sets. Further, growth of fish may be affected by tagging (Kelly and Barker, 1963; Saunders and Allen, 1967), including elasmobranch growth (Gruber, 1982; Parsons, 1987; Davenport and Stevens, 1988; Kalish and Johnston, 2001). Measurement error in body length of tagged and recaptured fish can also bias models; however, some methods of modeling data can incorporate measurement error as a parameter (Francis, 1988b). When sufficient tag-recapture data are available, models can be used to verify or compare growth rates and estimates of longevity (maximum age) and age at maturity with those from traditional age-based models (e.g., Natanson et al., 2002; Welsford and Lyle, 2005; Natanson and Deacy, 2019). One advantage of models based on tag-recapture data is that, if recapture data spans multiple seasons, information about growth variability and seasonal changes in growth can be determined (Francis, 1988b). Such information can be especially useful when comparing region-specific growth rates between or within populations.

The bonnethead (Sphyrna tiburo) is a relatively small shark species, with individuals reaching a maximum size of $150 \mathrm{~cm}$ total length, that is commonly found in the coastal and estuarine waters of the western North Atlantic Ocean from North Carolina to southern Brazil, including the Gulf of Mexico (GOM) and the Caribbean Sea (Compagno, 1984). Significant differences in life history characteristics exist between bonnetheads captured off the Atlantic coast of the southeastern United States (hereafter referred to as the Atlantic region) and those caught in the eastern GOM (Frazier et al., 2014). Regional variation in life history between populations in the Atlantic region and in the GOM has been found for other coastal shark species, including the Atlantic sharpnose shark (Rhizoprionodon terraenovae) (Carlson and Loefer ${ }^{1}$ ), blacknose shark (Carcharhinus acronotus) (Driggers et al., 2004), and finetooth shark (C. isodon) (Drymon et al., 2006; Vinyard et al., 2019).

The regional differences observed in bonnetheads are greater than those that have been described for any adjoining populations of other elasmobranch species. Significant differences in growth characteristics of bonnetheads have been found between populations in the GOM

\footnotetext{
${ }^{1}$ Carlson, J. K., and J. Loefer. 2007. Life history parameters for Atlantic sharpnose sharks, Rhizoprionodon terraenovae, from the United States South Atlantic Ocean and northern Gulf of Mexico. Southeast Data, Assessment, and Review SEDAR13-DW-08, 7 p. [Available from website.]
}

and the Atlantic region (Frazier et al., 2014). For the population in the Atlantic region, estimated maximum age (males: 12.0 years; females: 17.9 years) and age at $50 \%$ maturity (males: 3.9 years; females: 6.7 years) are more than twice the estimates for the population in the GOM (males: 5.5+ years for maximum age, 1.7 years for age at 50\% maturity; females: 7.5+ years for maximum age, 2.9 years for age at 50\% maturity) (Lombardi-Carlson et al., 2003; Frazier et al., 2014). Previous age and growth studies of bonnetheads in the eastern GOM (Parsons, 1993; Carlson and Parsons, 1997; Lombardi-Carlson et al., 2003) found significant latitudinal variation in life history traits; however, latitudinal variation has not been detected in the population off the Atlantic coast (Frazier et al., 2014). High degrees of site fidelity have been documented for this species (Heupel et al., 2006; Driggers et al., 2014), and tagging data indicate that there is no mixing between populations in the GOM and Atlantic region (Kohler and Turner, 2019).

The population status of bonnetheads in U.S. waters was most recently assessed as a single stock in 2013; however, because of observed differences in life history, tagging data, and genetic population structure, the results of that stock assessment were rejected and it was recommended that regional populations (i.e., those in the GOM and Atlantic region) be assessed as separate stocks (SEDAR, 2013). As such, the population status for both stocks is currently considered to be unknown (SEDAR, 2013).

Recent studies of bonnethead population structure (Escatel-Luna et al., 2015; Portnoy et al., 2015) found that the populations in the GOM and Atlantic region are genetically distinct, with evidence of fine-scale genetic structure within populations. Using a combination of mtDNA and nuclear single nucleotide polymorphisms, Portnoy et al. (2015) found evidence of female philopatry with male-mediated gene flow. Results of further analysis indicate that over half of a small sample of outlier single nucleotide polymorphism loci has signatures of latitudinal selection. Portnoy et al. (2015) proposed that philopatry can lead to adaptive variation on a local scale and that, when combined with sex-biased dispersal, adaptive variation can move among locations and environments. The high degree of site fidelity and latitudinal variation in life history observed for bonnetheads, in addition to localized adaption to environmental conditions, could explain the dissimilarities in life histories between populations in the different regions. However, differences in aging techniques, age estimation, or spatiotemporal biases could also explain observed differences (Campana, 2001; Cailliet and Goldman, 2004).

The objectives of this study were 1) to use 2 long-term mark-and-recapture data sets and an age-independent model, GROTAG, to estimate region-specific growth rates; 2) to generate estimates for age-independent life history parameters and compare results to region-specific estimates based on length-at-age data for verification of current life history information; and 3) to estimate region-specific seasonal growth and growth variability of bonnetheads in the GOM and the Atlantic region. 


\section{Materials and methods}

\section{Data collection}

Data sets from long-term mark-and-recapture studies were available from 2 regions (the northeastern GOM and estuarine waters of the Atlantic coast of the southeastern United States), corresponding to the areas within each region where published, region-specific age and growth studies occurred. Mark-recapture data were provided for 2 surveys conducted in the GOM. Mote Marine Laboratory provided data from fishery-independent gill-net surveys conducted from 1993 through 2006 in the eastern GOM (primarily from Yankeetown to Charlotte Harbor, Florida). Detailed descriptions of the survey methods used by Mote Marine Laboratory can be found in Hueter and Tyminski ${ }^{2}$ and in Hueter and Tyminski (2007). Data for the northeastern GOM were obtained for the period from 2003 through 2014 from the National Marine Fisheries Service from its Gulf of Mexico Shark Pupping and Nursery (GULFSPAN) survey. A fishery-independent survey conducted with gill nets made of multiple stretched-mesh panels, the GULFSPAN survey is used to assess populations of juvenile sharks from Cat Island, Mississippi, to Anclote Key, Florida, from April through October each year. Additional details about the GULFSPAN survey can be found in Bethea et al. (2015).

For the population in the Atlantic region, bonnethead mark-recapture data collected from 1998 through 2019 were available from the South Carolina Department of Natural Resources as part of its Cooperative Atlantic States Shark Pupping and Nursery (COASTSPAN) survey. The COASTSPAN survey is conducted in estuarine waters along the coast of South Carolina from Saint Helena Sound to Bulls Bay during April-September each year. Detailed descriptions of COASTSPAN survey methods can be found in Ulrich et al. (2007).

For all surveys, upon capture, the precaudal length, fork length (FL), total length, and stretch total length of each shark were measured in a straight line along the axis of the body to the nearest half centimeter (for sharks from the GOM) or nearest millimeter (for sharks from the Atlantic region). If healthy, sharks were tagged externally either with a nylon dart tag (142-mm tag, Hallprint Fish Tags $^{3}$, Hindmarsh Valley, Australia) or a FT-1-94 or T-bar Anchor Tag (Floy Tag Inc., Seattle, WA), at the base of the first dorsal fin (for both populations: GOM and Atlantic region), or with a $3.5-\mathrm{cm}$ rototag (Dalton ID Systems Ltd., Henley-on-Thames, UK), inserted through the cartilage of the leading edge of the first dorsal fin (for the population in the Atlantic region only). A limited number of individuals in the Atlantic region were double tagged with a

\footnotetext{
${ }^{2}$ Hueter, R. E., and J. P. Tyminski. 2002. U.S. shark nursery research overview, Center for Shark Research, Mote Marine Laboratory 1991-2001. Mote Mar. Lab. Tech. Rep. 816, 31 p. [Available from website.]

${ }^{3}$ Mention of trade names or commercial companies is for identification purposes only and does not imply endorsement by the National Marine Fisheries Service, NOAA.
}

rototag and a $12-\mathrm{mm}, 125-\mathrm{kHz}$ internal passive integrated transponder (Biomark Inc., Boise, ID) at the base of the first dorsal fin prior to release.

Upon recapture during a survey, the date of capture, tag number, capture location (latitude and longitude), and all aforementioned length measurements were recorded before a shark was rereleased. If a bonnethead was recaptured by a commercial or recreational fisherman (not during a survey), lengths, tag number, date of capture, and general capture location were requested. A subset of bonnetheads recaptured in the Atlantic region were sacrificed as part of age validation research (Frazier et al., 2014).

\section{Effects of tagging on growth}

Recaptured bonnetheads sacrificed and aged for agebased modeling of growth in a previous study (Frazier et al., 2014) were used in this study to test if there was any effect of tagging and tag type on growth. The residuals at recapture (i.e., at sacrifice, calculated as expected FL at age minus observed length at estimated age) used for analysis were from use of the final VBGF in Frazier et al. (2014). Residuals at initial capture (i.e., at tagging) were determined by using FL at initial tagging and estimated age at initial tagging (calculated as estimated age at sacrifice minus time at liberty) to remodel the data set. The change in residuals at initial capture and in residuals at recapture of sacrificed bonnetheads were plotted against time at liberty. If tagging or tag type had a negative effect on growth, most data points would be less than zero with the slope of the trendline significantly different from zero, indicating slower than predicted growth in tagged sharks.

\section{Modeling growth with tag-recapture data}

Growth increment data were modeled by using the Francis (1988b) method (i.e., by using the GROTAG model). In the event that a single individual was recaptured multiple times, only data from the initial capture and final recapture were used in analyses to give equal weight to each fish and to maximize time at liberty (Welsford and Lyle, 2005). Data for all recaptured sharks (excluding data as previously mentioned for sharks recaptured multiple times) were used in the model regardless of time at liberty, negative growth, or potential outliers because the GROTAG model can use these data to inform several calculated parameters. Growth has been found to be significantly different between sexes in previous growth studies (Parsons, 1993; Carlson and Parsons, 1997; Lombardi-Carlson et al., 2003; Frazier et al., 2014); therefore, sex-specific growth was modeled for both regions.

The GROTAG model, which includes an implementation of a maximum likelihood approach, was used to fit the VBGF (von Bertalanffy, 1938) to data for change in FL from initial capture to final recapture $(\Delta L)$ and for change in time at liberty $(\Delta T)$. The GROTAG model is a reparameterization of the Fabens growth model (Fabens, 1965) that incorporates seasonal growth. Mean annual growth $(g)$, 
measured in millimeters FL per year, was estimated at 2 user-defined reference lengths, $\alpha$ and $\beta$ (where $\alpha<\beta$ ). Reference lengths were chosen to ensure that the majority of lengths at initial capture $\left(L_{1}\right)$ fell between the 2 defined reference lengths by taking the mean length of the 3 smallest and 3 largest individuals at initial capture ( $\alpha$ and $\beta$, respectively; Dureuil and Worm, 2015) in each region-specific data set. These parameters have better statistical properties than the asymptotic length, or the theoretical maximum length $\left(L_{\infty}\right)$, and the growth constant $(k)$ because they are not highly correlated. Further, they allow easier interpretation of growth from tagging data (Francis, 1988b). The growth rates relate to the parameters of the von Bertalanffy growth curve as follows:

$$
\begin{aligned}
L_{\infty} & =\frac{\beta g_{\alpha}-\alpha g_{\beta}}{g_{\alpha}-g_{\beta}} \text { and } \\
\mathrm{e}^{-k} & =1+\frac{g_{\alpha}-g_{\beta}}{\alpha-\beta} .
\end{aligned}
$$

Seasonal growth is parameterized as $w$, the time of year when growth is at its maximum, and as $u$, with a $u$ value of 0.0 indicating no seasonal growth and a $u$ value of 1.0 indicating strong seasonal growth with growth likely ceasing at some point during the year:

$$
\Delta L=\left[\frac{\beta g_{\alpha}-\alpha g_{\beta}}{g_{\alpha}-g_{\beta}}-L_{1}\right]\left[1-\left(1+\frac{g_{\alpha}-g_{\beta}}{\alpha-\phi}\right)^{\Delta \mathrm{T}+\left(\phi_{2}-\phi_{1}\right)}\right],
$$

where $\phi_{\mathrm{i}}=u \frac{\sin \left[2 \pi\left(T_{\mathrm{i}}-w\right)\right]}{2 \pi}$ for $i=1,2$.

The GROTAG model is fit by minimizing the negative log-likelihood function $(-\lambda)$. Growth variability $(v)$ is incorporated into the model by the parameter $u_{\mathrm{i}}$, the expected mean growth increment of the $i$ th individual where $u_{\mathrm{i}}$ is normally distributed with a standard deviation (SD) of $\sigma_{i}$. In this study, $\sigma_{i}$ was assumed to be a function of the expected growth increment $\sigma_{\mathrm{i}}=v u_{\mathrm{i}}$. An additional parameter $p$, the probability of outlier contamination, was also fit. For each data set, made up of $i=1$ to $n$ growth increments where $R$ is the range (largest and smallest) of observed growth increments, the following equation was used:

$$
\lambda=\Sigma_{\mathrm{i}} \ln \left[(1-p) \lambda_{\mathrm{i}}+\frac{p}{R}\right],
$$

where $\lambda_{\mathrm{i}}=\exp \frac{-1 / 2\left(\Delta L_{\mathrm{i}}-u_{\mathrm{i}}-m\right)^{2} /\left(\sigma_{\mathrm{i}}^{2}+s^{2}\right)}{\left[2 \pi\left(\sigma_{\mathrm{i}}^{2}+s^{2}\right)\right]^{1 / 2}}$.

The likelihood function estimates the population measurement error in $\Delta L$ as being normally distributed with a mean of $m$ and an SD of $s$. The initial model estimated $g_{\alpha}, g_{\beta}$, and $v$ with additional parameters $(m, s, w, u$, and $p$ ) added, increasing model complexity (Table 1). Unfitted parameters were held at zero. Optimal model parameterization was determined for each region by using likelihood-ratio chi-square tests to determine if improvement in model fit was significant $(P<0.05)$. Francis $(1988 b)$ suggested that the introduction of an additional parameter

\section{Table 1}

Parameters fitted for the GROTAG models used to estimate region-specific growth rates of bonnetheads (Sphyrna tiburo) in the Gulf of Mexico during 1993-2006 and in the Atlantic Ocean off the southeastern United States during 1998-2019: growth rate estimates at reference lengths $\alpha$ and $\beta\left(g_{\alpha}\right.$ and $\left.g_{\beta}\right)$, mean $(m)$ and standard deviation $(s)$ of the measurement error, magnitude $(u)$ and timing $(w)$ of seasonal growth, growth variability $(v)$, and outlier contamination probability $(p)$.

\begin{tabular}{cl}
\hline GROTAG model & Parameters estimated \\
\hline 1 & $g_{\alpha}, g_{\beta}, s$ \\
2 & $g_{\alpha}, g_{\beta}, s, v$ \\
3 & $g_{\alpha}, g_{\beta}, s, v, m$ \\
4 & $g_{\alpha}, g_{\beta}, s, v, m, u, w, p$ \\
5 & $g_{\alpha}, g_{\beta}, s, p$ \\
\hline
\end{tabular}

should increase the log-likelihood value by at least 1.92 . Likelihood ratio tests were also conducted to determine significant differences in von Bertalanffy growth curves between regions (Kimura, 1980).

\section{Age-based growth model}

To allow direct comparison of growth estimates based on age data and those based on tag-recapture data, region-specific length-at-age data from Lombardi-Carlson et al. (2003) and Frazier et al. (2014) were remodeled (the authors of both publications used the Beverton and Holt, 1957, method of modeling VBGF parameters) by using an alternative parameterization of the VBGF recommended by Francis (1988a), in which mean length $(L)$ of fish of age $t$ is determined with this equation:

$$
L=l_{\Phi}+\frac{\left(l_{\Psi}-l_{\Phi}\right)\left(1-r^{2(\mathrm{t}-\Phi) / \Psi-\Phi}\right)}{1-r^{2}},
$$

where $r=\frac{l_{\Psi}-l_{\mathrm{X}}}{l_{\mathrm{X}}-l_{\Phi}}$,

where $X=(\Phi+\Psi) / 2$;

$l_{\Phi}=$ mean length at age $\Phi$;

$l_{\mathrm{X}}=$ mean length at age $\mathrm{X}$; and

$l_{\Psi}=$ mean length at age $\Psi$.

Values for $\Phi$ and $\Psi$ were chosen to encompass the range of ages represented in the published length-at-age data from both regions (Lombardi-Carlson et al., 2003; Frazier et al., 2014). The Francis (1988a) parameterization yields estimates of VBGF parameters that better represent the growth information modeled from length-at-estimatedage and tagging data. The growth estimates generated from this model allow comparison of the mean growth rate of fish of an estimated age with that of fish of a length equal to the mean length at that age (Francis, 1988a). 
Bootstrapping (with 5000 iterations) was used to develop 95\% confidence intervals (CIs) for VBGF parameter estimates. Model estimates and CIs were generated by using the FSA package (vers. 0.3.2; Ogle, 2012) in R (vers. 3.6.0; R Core Team, 2019).

\section{Comparisons of tag-recapture and age-based growth}

To compare growth rates between models, annual growth rates were estimated by using the parameters of the age and growth models to calculate mean length at estimated age. These values were used to create trend lines of the relationship between mean growth and FL, allowing comparison of the growth rates based on the GROTAG reference lengths. Parameter values from bootstrapping were used to calculate $95 \%$ CIs for the age-based growth rates.

To allow statistical and visual comparison of growth rates between the populations in the Atlantic region and GOM, we calculated growth at 2 reference lengths corresponding to the mean of the 3 smallest $L_{1}$ of sharks from the Atlantic region and a length less than the smallest age-based bootstrap $L_{\infty}$ estimate $\left(g_{\alpha}, g_{\beta}\right)$. Region-specific bootstrap values (from the use of 5000 iterations) were used to calculate average growth and 95\% CIs at the shared reference lengths. To allow comparisons of growth between age-based and length-based models, we calculated mean growth rates for age-based models $\left(g_{\alpha}^{\prime}, g_{\beta}^{\prime}\right)$ corresponding to growth rates from length-based models $\left(g_{\alpha}, g_{\beta}\right)$. These were calculated by using bootstrapped estimates of parameters $l_{\Phi}, l_{\mathrm{X}}$, and $l_{\Psi}$ to solve for age-based growth rates $\left(g_{\alpha}^{\prime}, g_{\beta}^{\prime}\right)$. The resulting values equate to the expected annual growth rate of fish at the age when mean length is equal to reference length $\alpha$ or $\beta$. The length-based $\left(g_{\alpha}, g_{\beta}\right)$ and age-based $\left(g_{\alpha}^{\prime}, g_{\beta}^{\prime}\right)$ growth rates were plotted with $95 \%$ CIs to allow comparisons of growth within and between regions and models. All GROTAG models were generated by using the fishmethods package (vers. 1.4-0; Nelson, 2013) in R.

For the GROTAG model, an additional parameter needed to produce von Bertalanffy growth curves, theoretical age at length zero $\left(t_{0}\right)$, was calculated by using model-specific $L_{\infty}$ and $k$ as well as observed mean size at birth $\left(L_{0}\right)$ with age $(t=0)$ :

$$
t_{0}=t+\left(\frac{1}{k}\right) \ln \left\{\frac{\left(L_{\infty}-L_{0}\right)}{L_{\infty}}\right\} .
$$

Region-specific mean $L_{0}$ was $263 \mathrm{~mm}$ FL for sharks from the Atlantic region (Frazier et al., 2014) and $252 \mathrm{~mm} \mathrm{FL}$ for sharks from the GOM (R. Hueter, unpubl. data).

\section{Longevity and age at $50 \%$ maturity}

Estimated maximum ages from the region-specific age and growth studies provided initial values of maximum age; however, these values are likely underestimated in a fished population (Bishop et al., 2006). For the age-based and length-based models, longevity was estimated for each region and sex. The recaptured shark with the greatest time at liberty was assigned an age at initial capture by using $L_{1}$ and model-specific VBGF parameters reconfigured to solve for age where

$$
\text { Age }=\left(\frac{\ln \left(1-\frac{L_{1}}{L_{\infty}}\right)}{-k}\right)+t_{0} \text {. }
$$

This calculated age at initial capture was then added to time at liberty to estimate longevity.

The GROTAG-derived VBGF parameters were used to solve for sex-specific age at 50\% maturity by using equation 7 with $L_{1}$ set to estimates of length at $50 \%$ maturity of sharks from the Atlantic Ocean (male: $617.8 \mathrm{~mm}$ FL; female: $818.5 \mathrm{~mm}$ FL; Frazier et al., 2014) and the GOM (male: $630.8 \mathrm{~mm}$ FL; female: $716.4 \mathrm{~mm}$ FL; LombardiCarlson ${ }^{4}$ ), allowing calculation of age at $50 \%$ maturity without introducing bias from age estimation. Confidence intervals for longevity and age at 50\% maturity were generated by using the $95 \%$ CIs for the VBGF parameters. For the published estimates of age at $50 \%$ maturity, $95 \% \mathrm{CIs}$ are recorded as published for the population in the Atlantic region; however, no measurements of uncertainty were reported for the population in the GOM.

\section{Results}

\section{Data collection}

A total of 139 and 190 recaptured bonnetheads were available from the GOM and the Atlantic Ocean off the southeastern United States, respectively (Fig. 1). Ranges of lengths at capture and recapture and range and mean of time at liberty, by region and sex, are reported in Table 2. Sex- and region-specific recapture data sets did not encompass the range of lengths that have been reported as present in each region's population (Ulrich et al., 2007; Bethea et al., 2015). Large females were lacking in the GOM data set ( $n=99$, only 2 females greater than $880 \mathrm{~mm}$ FL available; Suppl. Table), and there was no representation of small females in the Atlantic region data set $(n=172$, no females less than $550 \mathrm{~mm}$ FL present; Table 2). Sample sizes for males from the GOM $(n=40)$ and the Atlantic region $(n=18)$ were relatively small, and lengths did not adequately represent the range of individuals found in the population, especially in the Atlantic region (Table 2, Suppl. Table). In comparison, the smallest and largest bonnetheads in the data used in the age-based models for fish in the Atlantic region are 245 and $825 \mathrm{~mm} \mathrm{FL} \mathrm{(males)}$ and 262 and $1043 \mathrm{~mm}$ FL (females) (Frazier et al., 2014), and those in the data used in the GOM age-based models

\footnotetext{
${ }^{4}$ Lombardi-Carlson, L. A. 2007. Life history traits of bonnetheads, Sphyrna tiburo, from the eastern Gulf of Mexico. Southeast Data, Assessment, and Review SEDAR13-DW-24, 7 p. [Available from website.]
} 


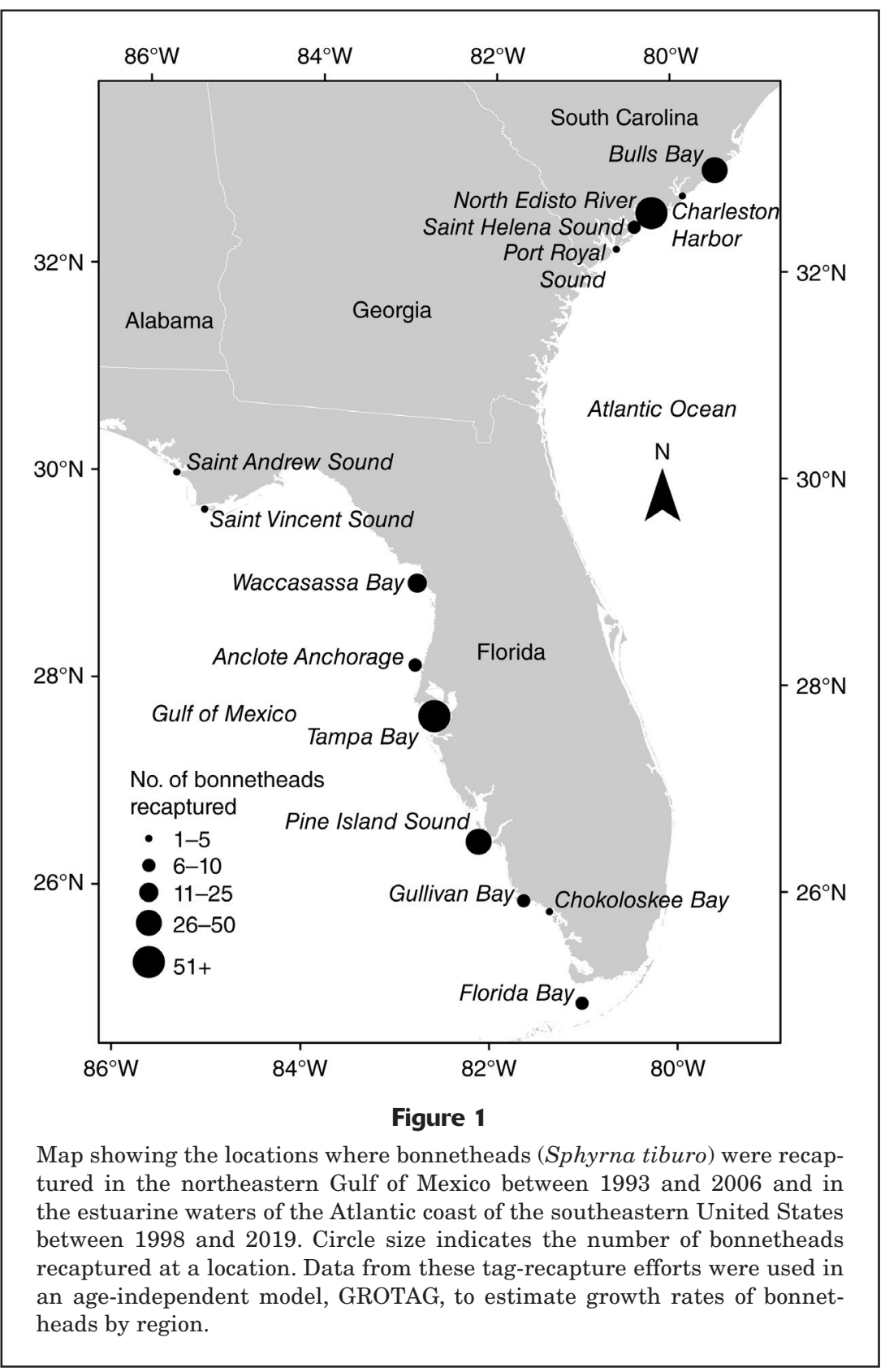

slopes bound zero (all tags: $b=0.005[95 \%$ CI -0.033-0.043], $P=0.615$, df=20; nylon dart tag: $b=0.037$ [95\% CI $-0.109-0.184$ ], $P=0.554, \mathrm{df}=6$; rototag: $b=0.005[95 \%$ CI $-0.042-0.052], P=0.805, \mathrm{df}=12)$. Therefore, there is no evidence to indicate that tagging or tag type affected growth, and growth increments from tag-recapture data were considered suitable for modeling growth in a population.

\section{Models based on tag-recapture data}

The GROTAG model (Francis, 1988b) produced biologically reasonable parameter estimates for males from both regions (Table 3); however, 95\% CIs are large, indicating that the sample size was insufficient to produce robust estimates of growth. The best-fit model for males in the GOM (model 3) included parameters for mean growth rates at reference lengths $\left(g_{470}, g_{737}\right)$, mean and $\mathrm{SD}$ of measurement error, and growth variability; the model failed to converge when the model 1 configuration was used (Table 4). The final model for males in the Atlantic region (model 2) included parameters for mean growth rates at reference lengths $\left(g_{612}, g_{765}\right)$, SD of measurement error, and growth variability; model 3 failed to fit the data for this region (Table 4). Estimates of growth variability and seasonal growth for males are uninformative because the low sample size produced large $95 \% \mathrm{CIs}$ for estimates, with upper and lower limits of $95 \%$ CIs above parameter bounds in the GOM model. Although confidence intervals are large and overlap, the SD of measurement error of the GOM model is 3 times that of the Atlantic region model.

Region-specific models for female bonnetheads converged for all models run. The final model for females in the GOM

are 300 and $760 \mathrm{~mm}$ FL (males) and 340 and $960 \mathrm{~mm}$ FL (females) (Lombardi-Carlson et al., 2003).

\section{Effects of tagging on growth}

A total of 22 recaptured individuals were aged by Frazier et al. (2014), and resulting data were available for analysis of the effect of tag type on growth (8 sharks were tagged with a nylon dart tag, and 14 sharks were tagged with a rototag). The changes in residuals from mean age at initial capture (i.e., tagging) and estimated age at recapture were plotted against time at liberty (Fig. 2). The slope (b) of the line is not significantly different from zero for tag types combined or for individual tag types, and 95\% CIs for (model 2) included parameters for mean growth rates at reference lengths $\left(g_{465}, g_{915}\right)$, SD of measurement error, and growth variability (Table 4 ). The final model for females in the Atlantic region (model 4) is more complex, with the parameters for mean growth rates at reference lengths $\left(g_{555}, g_{1000}\right)$, mean and SD of measurement error, growth variability, and seasonal variation included (Table 4 ). The estimates of growth variability for females are large from both the GOM model $(v=0.63)$ and the Atlantic region model $(v=0.56)$, indicating that individuals in the population could be expected to grow $0.37-1.63$ (GOM) or 0.44-1.56 (Atlantic region) times the estimated average growth rate per length class. The model for females in the Atlantic region has a strong seasonal growth component 


\begin{tabular}{|c|c|c|c|c|c|c|}
\hline \multicolumn{7}{|c|}{ Table 2} \\
\hline \multicolumn{7}{|c|}{$\begin{array}{l}\text { Summary of data collected for bonnetheads (Sphyrna tiburo) tagged and recaptured in the } \\
\text { northeastern Gulf of Mexico (GOM) during 1993-2006 and in the Atlantic Ocean off the } \\
\text { southeastern United States (Atlantic region) during 1998-2019. The number of individuals } \\
\text { recaptured }(n) \text {, the range of fork lengths (FLs) of fish at initial capture and recapture, and } \\
\text { the range, mean, and standard deviation (given in parentheses) of times at liberty for recap- } \\
\text { tured sharks are provided by region and sex. }\end{array}$} \\
\hline Region & Sex & $n$ & $\begin{array}{c}\text { Initial } \\
\text { FL (mm) }\end{array}$ & $\begin{array}{l}\text { Recapture } \\
\text { FL (mm) }\end{array}$ & $\begin{array}{l}\text { Time at } \\
\text { liberty }(\mathrm{d})\end{array}$ & $\begin{array}{c}\text { Mean time at } \\
\text { liberty (d) }\end{array}$ \\
\hline \multirow[t]{2}{*}{ GOM } & $\mathrm{F}$ & 99 & $430-930$ & $450-958$ & $1-2028$ & $308(366)$ \\
\hline & $\mathrm{M}$ & 40 & $400-750$ & $520-780$ & $1-1639$ & 259 (319) \\
\hline \multirow[t]{2}{*}{ Atlantic region } & $\mathrm{F}$ & 172 & $550-1013$ & $642-1014$ & $10-3263$ & $458(518)$ \\
\hline & M & 18 & $532-767$ & $543-805$ & $13-2659$ & $401(823)$ \\
\hline
\end{tabular}

( $u=1.0, w=0.58$ ), indicating that growth likely ceases at some point during the year and that it peaks in June. The $\mathrm{SD}$ of the measurement error for the model for females in the GOM ( $s=11.9 \mathrm{~mm} \mathrm{FL})$ is more than double that of the model for females in the Atlantic region ( $s=4.8 \mathrm{~mm} \mathrm{FL})$ with $95 \%$ CIs that do not overlap, indicating significant differences in measurement error between the 2 regions. The model for females in the Atlantic region had a negligible mean measurement error of $-0.5 \mathrm{~mm}$ FL. The contamination probability parameter was not included in 3 of the 4 models and is very low $(p<0.001)$ in the model for females in the Atlantic region; therefore, the occurrence of outliers is scarce in all data sets.

\section{Age-based growth model and regional comparisons}

The Francis (1988a) age-based model produced nearly identical estimates of VBGF parameters to those produced by using the Beverton and Holt (1957) modeling method reported in Frazier et al. (2014).

For both regions, the age-based models for males predicted faster mean annual growth at smaller lengths and slower growth than the length-based models as bonnetheads approached estimated $L_{\infty}$ (Fig. 3). For males in the Atlantic region, 95\% CIs for age-based estimates of growth rates overlap at GROTAG-predicted rates for both $g_{612}$ and $g_{765}$ (Fig. 3). For males in the GOM, 95\% CIs overlap at GROTAG-predicted rates for $g_{470}$; however, at $g_{737}, 95 \%$ CIs do not overlap and rates are significantly different from those from the age-based model, with the age-based model predicting near zero growth by an FL of $708 \mathrm{~mm}$ (Fig. 3).

For females from the Atlantic region, the age-based model predicted a faster growth rate at smaller lengths but very similar growth rates at larger lengths compared with predicted rates from the GROTAG model (Fig. 4), and $95 \%$ CIs overlap at both $g_{555}$ and $g_{1000}$. For females in the GOM, the age-based model predicted nearly identical growth rates at the smaller GROTAG reference length $\left(g_{465}\right)$; however, the age-based model predicted a much smaller $L_{\infty}$ than the estimate from the GROTAG model (Fig. 4). The predicted growth rate at the larger reference length $\left(g_{915}\right)$ is significantly higher than the estimate from the age-based model, with no overlap in $95 \%$ CIs. The significant differences in estimated growth rates for both males and females at $g_{737}$ and $g_{915}$ between the GROTAG and age-based models indicate sampling bias or age underestimation in the GOM age-based model.

Plots of growth rates and 95\% CIs estimated for males with the GROTAG model do not indicate significant differences in growth between populations in the Atlantic region and the GOM (Fig. 3); however, results from likelihood-ratio tests $\left(\chi^{2}=40.8, \mathrm{df}=3, P<0.001\right)$ indicate significant differences in growth between regions.

Plots of growth rates with 95\% CIs estimated for females as well as results from likelihood-ratio tests $\left(\chi^{2}=31.2, \mathrm{df}=3, P<0.001\right)$ for the best-fit GROTAG models indicate that growth was significantly different between regions, with a significant difference in average growth rates occurring in individuals larger than $\sim 850 \mathrm{~mm} \mathrm{FL}$ (Fig. 4). Plots of von Bertalanffy growth curves by sex, region, and model further illustrate the difference in predicted lengths at age (Fig. 5); however, caution should be used when comparing curves between the GROTAG and age-based models because of different definitions of $L_{\infty}$ (Francis, 1988a).

To allow comparisons of growth within and between models and regions, growth rates were calculated for 2 reference lengths $\left(g_{555}, g_{830}\right)$ by using the GROTAG and agebased models. Plots of bootstrap parameter estimates from the GROTAG model indicate clear differences in $g_{830}$ between regions with no overlap in 95\% CIs (Fig. 6). Plots of GROTAG bootstrap parameter estimates indicate less variation in growth with greater length for both regions. Overall, given the estimates from both models, the variation in predicted growth is much higher for the population in the GOM than for the population in the Atlantic region. At the set reference lengths, growth rates do not significantly differ between the age-based and GROTAG models; however, as presented in Figure 3, estimated growth rates 


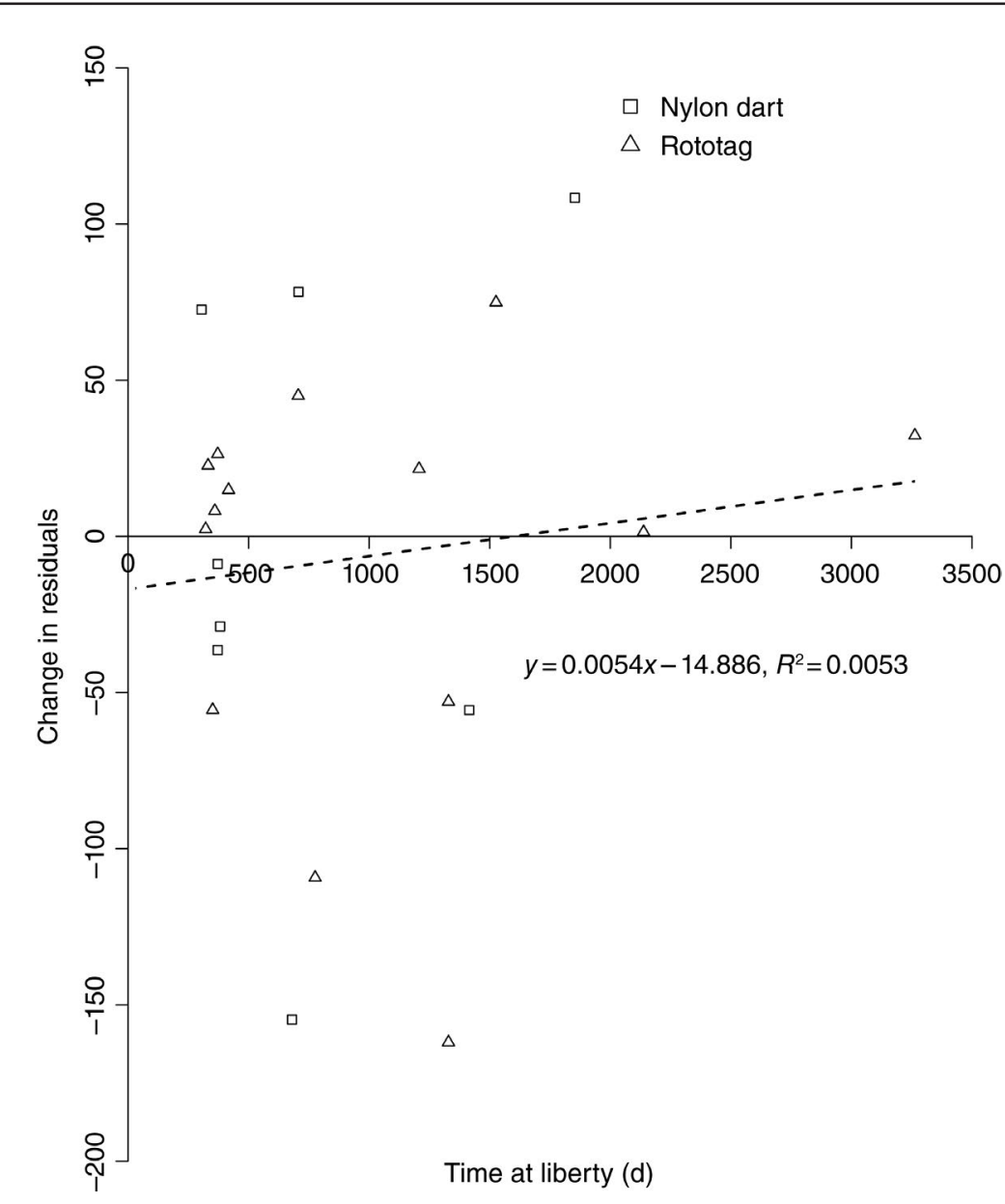

Figure 2

Changes in residuals for ages of recaptured bonnetheads (Sphyrna tiburo) in the estuarine waters of the Atlantic coast of the southeastern United States plotted against their times at liberty, by type of tag: nylon dart (squares) and rototag (triangles). If tagging has a negative effect on growth, the majority of data points should be negative and the slope of the dashed line should be significantly different from zero. The equation for the trend line and the coefficient of multiple determination $\left(R^{2}\right)$ are provided. Residuals were calculated by using lengths at initial tagging and at recapture and by using ages and the von Bertalanffy growth curve from Frazier et al. (2014).

deviate between models as individuals grow beyond the upper reference length.

\section{Longevity and age at $50 \%$ maturity}

For the population in the GOM, data for recaptured bonnetheads from long-term tag-recapture studies, a male and a female with times at liberty of 1639 and $1833 \mathrm{~d}$ and initial FLs of 600 and $800 \mathrm{~mm}$, respectively, were used to calculate maximum age in each model. For the population in the Atlantic region, data for a recaptured male and a recaptured female, with times at liberty of 2659 and $3263 \mathrm{~d}$ and FLs of 763 and $980 \mathrm{~mm}$, respectively, were used. Calculated ages from the GROTAG model are larger than those from the age-based models for both regions, although 95\% CIs overlap (Table 3). For sharks in the GOM, published estimated maximum ages are significantly below calculated maximum ages from models based on age and on tag-recapture data, with published values below 95\% CIs for all models with the exception of the GROTAG model used for estimating growth of males; a lower limit of the $95 \%$ CI could not be estimated because of the size of the tagged shark used in relation to the lower limit of the 95\% CI for the estimate of $L_{\infty}$. For bonnetheads in the Atlantic region, calculated maximum ages are also significantly larger than published estimates, with the lower limit of the 95\% CI falling above maximum estimated age for all models.

Published estimates of age at 50\% maturity are lower than those calculated by using the GROTAG models (Table 3 ). We were unable to calculate the lower limit of the $95 \%$ CI for age at $50 \%$ maturity of males with either GROTAG model, and 95\% CIs based on the GOM data were not published; therefore, we cannot determine if differences are significant for these estimates. Upper and lower confidence intervals for estimates from both length-based and age-based models were available only for females in the Atlantic region. Although the GROTAG model for females in the Atlantic region produced an estimate of age at $50 \%$ maturity that is slightly larger than that from the age-based model, 95\% CIs for the estimates overlap.

\section{Discussion}

This study confirms previously published significant differences in regionspecific growth and life history characteristics of bonnetheads between the northeastern GOM and the Atlantic region by using age-independent methods of modeling growth. Growth rates, age at 50\% maturity, and longevity all differ for both sexes between these 2 regions. Despite low sample sizes and poor coverage of ranges of lengths for males, we were able to produce reasonable growth estimates for the populations in the northeastern GOM and the Atlantic region by using the GROTAG model; however, we were unable to determine significance of some life history characteristics because of the high uncertainty in estimates of growth and growth parameters. The low sample sizes of males from the Atlantic region available for growth modeling is reflective of the nearshore distribution of male bonnetheads, with tagging effort heavily skewed toward females in estuarine waters where most fishery-independent sampling and tagging 


\section{Table 3}

Estimates of von Bertalanffy growth function (VBGF) parameters, maximum age, and age at 50\% maturity from GROTAG models based on tag-recapture data and from age-based models for male and female bonnetheads (Sphyrna tiburo) from the northeastern Gulf of Mexico (GOM) and the Atlantic Ocean off the southeastern United States (Atlantic region). The VBGF parameters, asymptotic length $\left(L_{\infty}\right)$, coefficient of growth $(k)$, and theoretical age at length zero $\left(t_{0}\right)$, are provided with $95 \%$ confidence intervals, which were generated by using bootstrapping (with 5000 iterations). Also provided are published estimates of maximum age (Lombardi-Carlson et al., 2007; Frazier et al., 2014). Ages at 50\% maturity were estimated in GROTAG models by using lengths at 50\% maturity published in Lombardi-Carlson et al. (2007) and Frazier et al. (2014). Data used in the models are from sharks tagged and recaptured in the GOM during 1993-2006 and in the Atlantic region during 1998-2019. FL=fork length.

\begin{tabular}{|c|c|c|c|c|c|c|c|c|c|}
\hline Model & Region & Sex & $n$ & $\begin{array}{c}L_{\infty} \\
(\mathrm{mm} \mathrm{FL})\end{array}$ & $k$ & $\begin{array}{c}t_{0} \\
\text { (years) }\end{array}$ & $\begin{array}{c}\text { Age at } 50 \% \\
\text { maturity } \\
\text { (years) }\end{array}$ & $\begin{array}{l}\text { Maximum } \\
\text { age } \\
\text { (years) }\end{array}$ & $\begin{array}{c}\text { Published } \\
\text { maximum } \\
\text { age } \\
\text { (years) }\end{array}$ \\
\hline \multirow[t]{4}{*}{ GROTAG } & GOM & M & 40 & $\begin{array}{l}769.6 \\
604.2-823.5\end{array}$ & $\begin{array}{l}0.254 \\
0.470-0.087\end{array}$ & $\begin{array}{l}-1.56 \\
-(1.14-4.19)\end{array}$ & $\begin{array}{l}5.2 \\
\infty-12.5\end{array}$ & $\begin{array}{l}8.9 \\
\infty-15.3\end{array}$ & \\
\hline & & $\mathrm{F}$ & 99 & $\begin{array}{l}948.3 \\
921.2-967.9\end{array}$ & $\begin{array}{l}0.243 \\
0.313-0.184\end{array}$ & $\begin{array}{l}-1.27 \\
-(1.02-1.64)\end{array}$ & $\begin{array}{l}4.5 \\
3.8-5.7\end{array}$ & $\begin{array}{l}11.4 \\
9.7-14.3\end{array}$ & \\
\hline & Atlantic region & M & 18 & $\begin{array}{l}814.8 \\
533.4-1135.6\end{array}$ & $\begin{array}{l}0.166 \\
0.386-0.070\end{array}$ & $\begin{array}{l}-2.35 \\
-(1.76-3.76)\end{array}$ & $\begin{array}{l}6.2 \\
\infty-7.5\end{array}$ & $\begin{array}{l}21.5 \\
19.4-\infty\end{array}$ & \\
\hline & & $\mathrm{F}$ & 172 & $\begin{array}{l}1039.5 \\
1027.7-1048.5\end{array}$ & $\begin{array}{l}0.170 \\
0.191-0.145\end{array}$ & $\begin{array}{l}-1.75 \\
-(1.54-1.99)\end{array}$ & $\begin{array}{l}7.4 \\
6.8-8.5\end{array}$ & $\begin{array}{l}24.0 \\
23.5-25.8\end{array}$ & \\
\hline \multirow[t]{4}{*}{ Age based } & GOM & M & 245 & $\begin{array}{l}703.3 \\
663.8-765.2\end{array}$ & $\begin{array}{l}0.538 \\
0.753-0.386\end{array}$ & $\begin{array}{l}-1.60 \\
-(1.10-2.25)\end{array}$ & $2.0+$ & $\begin{array}{l}6.5 \\
6.4-6.6\end{array}$ & $5.5+$ \\
\hline & & $\mathrm{F}$ & 254 & $\begin{array}{l}895.0 \\
842.9-970.3\end{array}$ & $\begin{array}{l}0.282 \\
0.334-0.226\end{array}$ & $\begin{array}{l}-2.13 \\
-(1.82-2.55)\end{array}$ & $3.0+$ & $\begin{array}{l}10.8 \\
10.2-12.1\end{array}$ & $7.5+$ \\
\hline & Atlantic region & M & 216 & $\begin{array}{l}779.8 \\
761.5-799.7\end{array}$ & $\begin{array}{l}0.296 \\
0.320-0.274\end{array}$ & $\begin{array}{l}-1.51 \\
-(1.35-1.68)\end{array}$ & $\begin{array}{l}3.9 \\
3.5-4.2\end{array}$ & $\begin{array}{l}18.7 \\
16.8-\infty\end{array}$ & 16.0 \\
\hline & & $\mathrm{F}$ & 329 & $\begin{array}{l}1032.3 \\
1011.6-1053.9\end{array}$ & $\begin{array}{l}0.188 \\
0.179-0.198\end{array}$ & $\begin{array}{l}-1.76 \\
-(1.59-1.94)\end{array}$ & $\begin{array}{l}6.7 \\
6.4-7.1\end{array}$ & $\begin{array}{l}23.0 \\
21.9-24.9\end{array}$ & 17.9 \\
\hline
\end{tabular}

occurs (Ulrich et al., 2007). In the GOM, the lower number of male bonnetheads that were recaptured is a result of the primary habitat of male bonnetheads being outside of or on the periphery of the area where sampling occurred and where tags were deployed. Therefore, fewer males than females were tagged and consequently recaptured. Future efforts should focus on sampling and tagging male bonnetheads, especially those in early life stages, to decrease uncertainty in results from length-based models.

Although it is difficult to determine the effects of tagging on growth in wild fish populations, our results do not provide evidence indicating that tagging and tag type affected growth. Growth was variable in the first year after tagging, with a larger number of individuals experiencing slower growth than expected. This slow growth, however, could be due to the short-term effects of the stress from being captured rather than the effect of the tag on the individual (Gruber, 1982; Parsons, 1987; Davenport and Stevens, 1988; Skomal and Bernal, 2010). Over the long term, we found no evidence of effects of tagging on growth of captured bonnetheads, and all individuals at liberty for over 4 years grew older and larger than the age and length predicted by the age-based growth model. These findings contrast with those of studies on lemon sharks (Negaprion brevirostris) (Manire and Gruber, 1991; Oliveira, 2001) and northern pike (Esox lucius) (Scheirer and Coble, 1991) that indicate that growth could be impaired by up to $50 \%$ in tagged individuals when a variety of tag types were used. Results of other growth studies (e.g., Jensen, 1967; Jolivet et al., 2009) indicate that there were no significant effects of tagging on growth; therefore, it is possible that there may be effects specific to species, life stage, or tag type. Caution should be used in interpreting growth data from recaptured individuals to the population level without investigating these effects.

The final GROTAG models for males in both regions included SD of measurement error and growth variability, and the GOM model has the added parameter of mean measurement error. Estimates of growth variability are unreliable because of low sample size, and 95\% CIs contain values that are not above and below parameter limits; therefore, no comparisons can be made with these parameters. The final GROTAG models for males and females in the GOM both have large estimates of SD of measurement error compared with those from the models for males and females in the Atlantic region; however, this result was not unexpected. For individuals from the GOM, length was measured to the nearest half centimeter, and several biologists and interns measured fish; whereas, bonnetheads from the Atlantic region were measured to the nearest millimeter by only 2 individuals. The use of fewer individuals to measure all captured specimens and the smaller measurement increment likely led to more precise 


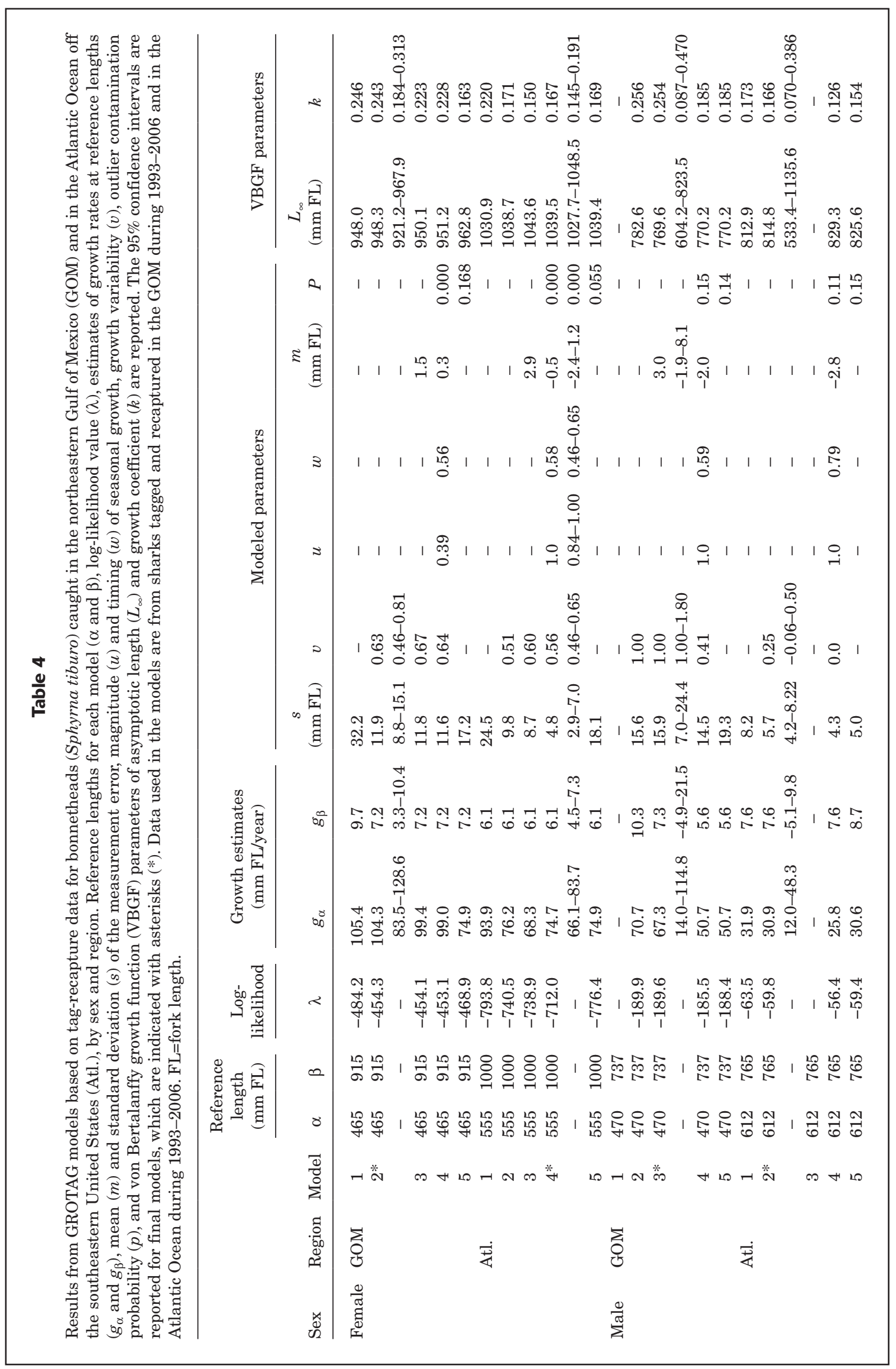




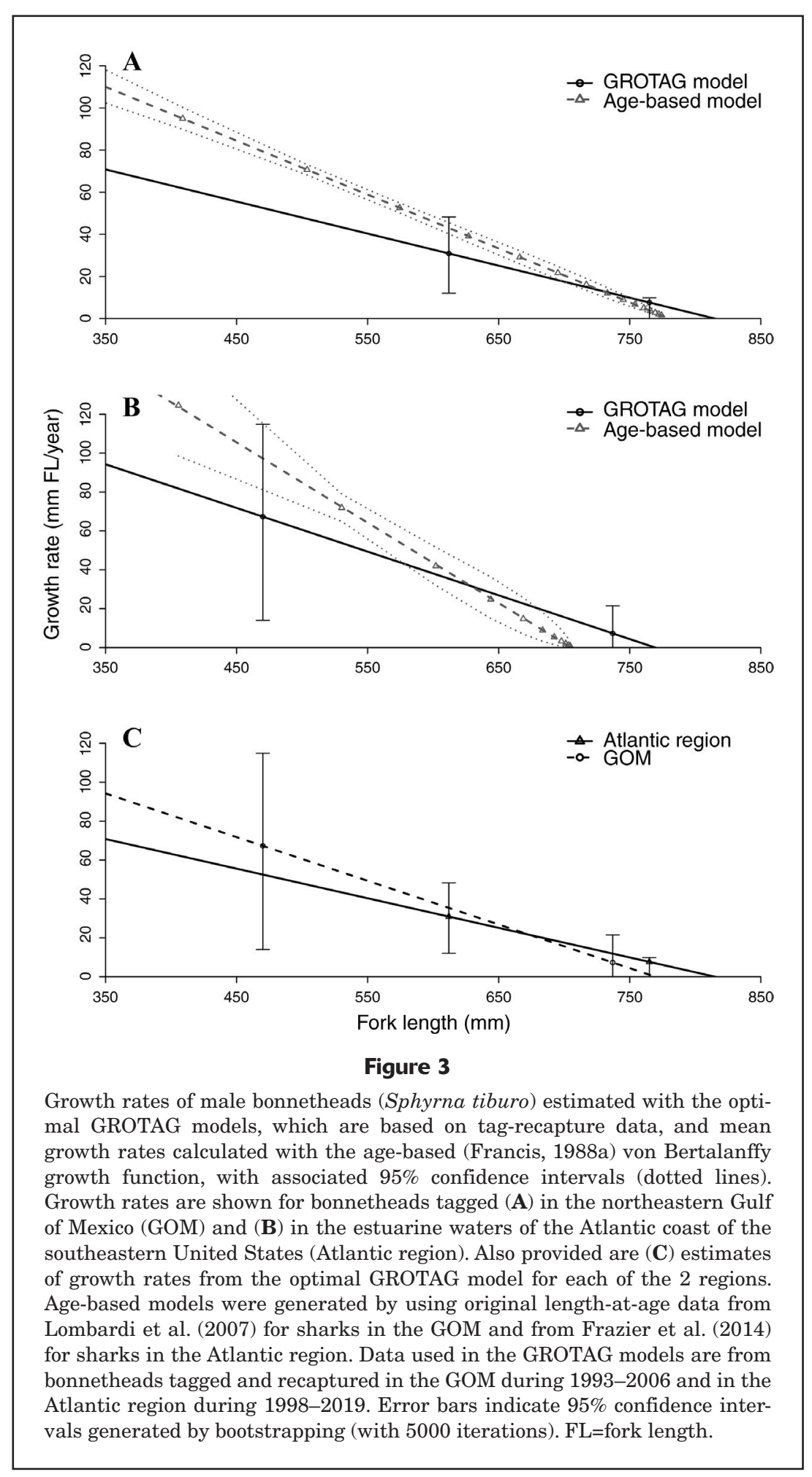

and differences in these growth rates may be an artifact of sample size given the observed 95\% CIs. Regardless, these variability estimates are among the highest published values for elasmobranchs with values ranging from 0.06 for the tope (Galeorhinus galeus) (Francis and Mulligan, 1998) to 0.58 for the spotted estuary smooth-hound (Mustelus lenticulatus) (Francis and Francis, 1992), with most falling in a range of $0.15-0.40$ (e.g., Simpfendorfer, 2000; Meyer et al., 2014; Natanson and Deacy, 2019).

Results from the final GROTAG models indicate a strong seasonal growth pattern in the population in the Atlantic region $(u=1)$ but not in the population in the GOM (the seasonal growth parameter was not included in the final GOM model). Latitudinal variation in growth has been previously detected for bonnetheads in the GOM but not for those in the Atlantic region (Parsons, 1993; Carlson and Parsons, 1997; LombardiCarlson et al., 2003; Frazier et al., 2014).

The more variable growth for sharks in the GOM and lack of a seasonal signal may indicate that there are differences within the population in growth along the western coast of Florida, where sampling for this study occurred. Site fidelity has been established for bonnetheads in both the Atlantic region and the GOM (Heupel et al., 2006; Driggers et al., 2014), and bonnetheads are known to make predictable temperature-driven migrations in response to declining water temperatures (Ulrich et al., 2007; Driggers et al., 2014). In the Atlantic region, all bonnetheads were tagged and recaptured within their established summer range. In the GOM, bonnetheads were also predominantly captured and recaptured during summer months; however, capture and recapture of sharks took place at multiple locations along the coast. Because these sampled subpopulations likely have site fidelity to their area of capture, they likely experience differential growth due to differences in water temperatures (Carlson and Parsons, 1999; Pistevos et al., 2015), in food availabilmeasurements at tagging and recapture and consequently lower chances of errors in measurement.

Results from the final GROTAG models for females indicate that growth is more variable for bonnetheads from the GOM $(v=0.63)$ than for those from the Atlantic region $(v=0.56)$; however, these differences are not significant ity or energetic value of food (Bethea et al., 2007; Vucic-Pestic et al., 2011), and in energetic needs during winter migrations necessary to find optimum water temperatures for overwintering (Carlson and Parsons, 1999; Hoffmayer et al., 2006). However, the lack of a detection of seasonal growth patterns and greater growth 

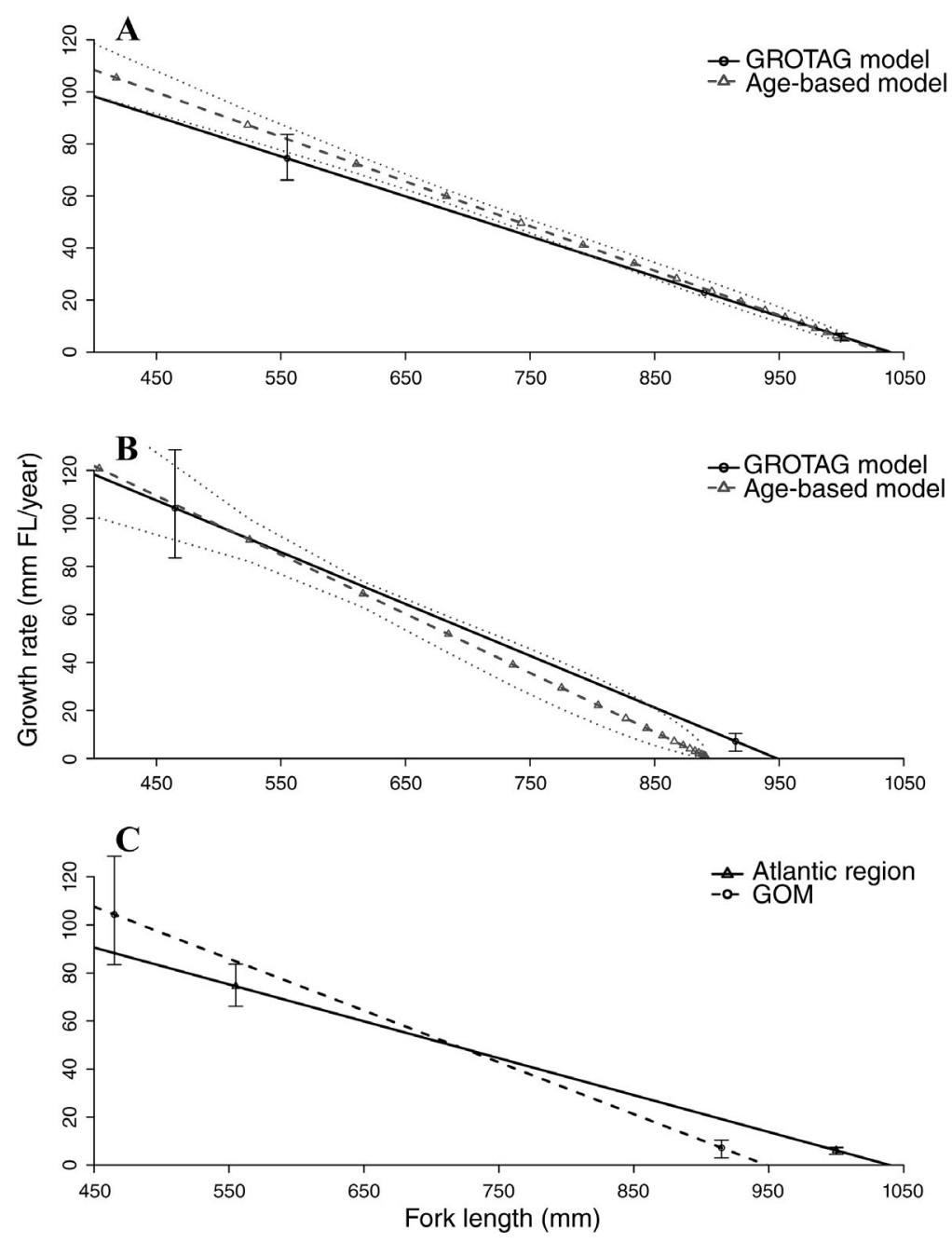

Figure 4

Growth rates of female bonnetheads (Sphyrna tiburo) estimated with the optimal GROTAG models, which are based on tag-recapture data, and mean growth rates calculated with the age-based (Francis, 1988a) von Bertalanffy Growth rates are shown for bonnetheads tagged (A) in the northeastern Gulf of Mexico (GOM) and (B) in the estuarine waters of the Atlantic coast of the southeastern United States (Atlantic region). Also provided are (C) estimates of growth rates from the optimal GROTAG model for each of the 2 regions. Age-based models were generated by using original length-at-age data from Lombardi et al. (2007) for sharks in the GOM and from Frazier et al. (2014) for sharks in the Atlantic region. Data used in the GROTAG models are from bonnetheads tagged and recaptured in the GOM during 19932006 and in the Atlantic region during 1998-2019. Error bars indicate 95\% confidence intervals generated by bootstrapping (with 5000 iterations). $\mathrm{FL}=$ fork length. growth function, with associated 95\% confidence intervals (dotted lines).

Results from GROTAG models confirm previously published differences in growth between the 2 regions. Both males and females in the GOM had faster average growth at smaller lengths and slower growth with a smaller $L_{\infty}$ than bonnetheads from the Atlantic region. Visual inspection of 95\% CIs does not reveal significant differences between regions because of large uncertainty caused by low sample sizes, but results of likelihood-ratio tests confirm differences in growth. Significant differences in growth have been detected for other coastal migratory sharks (Carlson and Baremore, 2003; Driggers et al., 2004; Vinyard et al., 2019); however, the reasons for these regional growth differences are unknown.

Growth curves derived from GROTAG and age-based models are not directly comparable; instead, Francis (1988a) suggested that comparisons of growth rates between data types are more appropriate. All GROTAG models predicted slower initial growth and faster growth at longer lengths compared with estimates from age-based models. The slower estimated initial growth rates likely result from a lack of tagged youngof-the-year bonnetheads in all 4 data sets, likely a combination of gear bias and variation in spatial distribution of young-of-the-year bonnetheads (Driggers et al., 2014). The GROTAG model for females in the GOM is based on the largest sample size of tagged and recaptured juvenile bonnetheads (including individuals tagged as small as $400 \mathrm{~mm} \mathrm{FL}$ ) and, consequently, the best agreement between model growth rates at small lengths. However, growth rates are significantly different at long lengths. Estimates from the GROTAG model for females in the Atlantic region have excellent agreement with those from the agebased model, especially as lengths reach predicted $L_{\infty}$. Parameters of the VBGF are not significantly different between models, confirming estimated growth from the age-based model for females in the Atlantic region. Although the VBGF parameters are defined differently for variation may also be artifacts of sample size. Future efforts should focus on continued tagging of bonnetheads in these regions because a more robust data set would allow age-independent comparisons of growth and, therefore, determination of latitudinal differences in growth within the GOM. the length-at-age data and tag-recapture data, the results of other studies indicate that models based on tag-recapture data can produce growth curves that are similar to those from age-based models (Natanson et al., 2002).

The GROTAG models for males and females predicted significantly faster growth at longer lengths, larger $L_{\infty}$, 


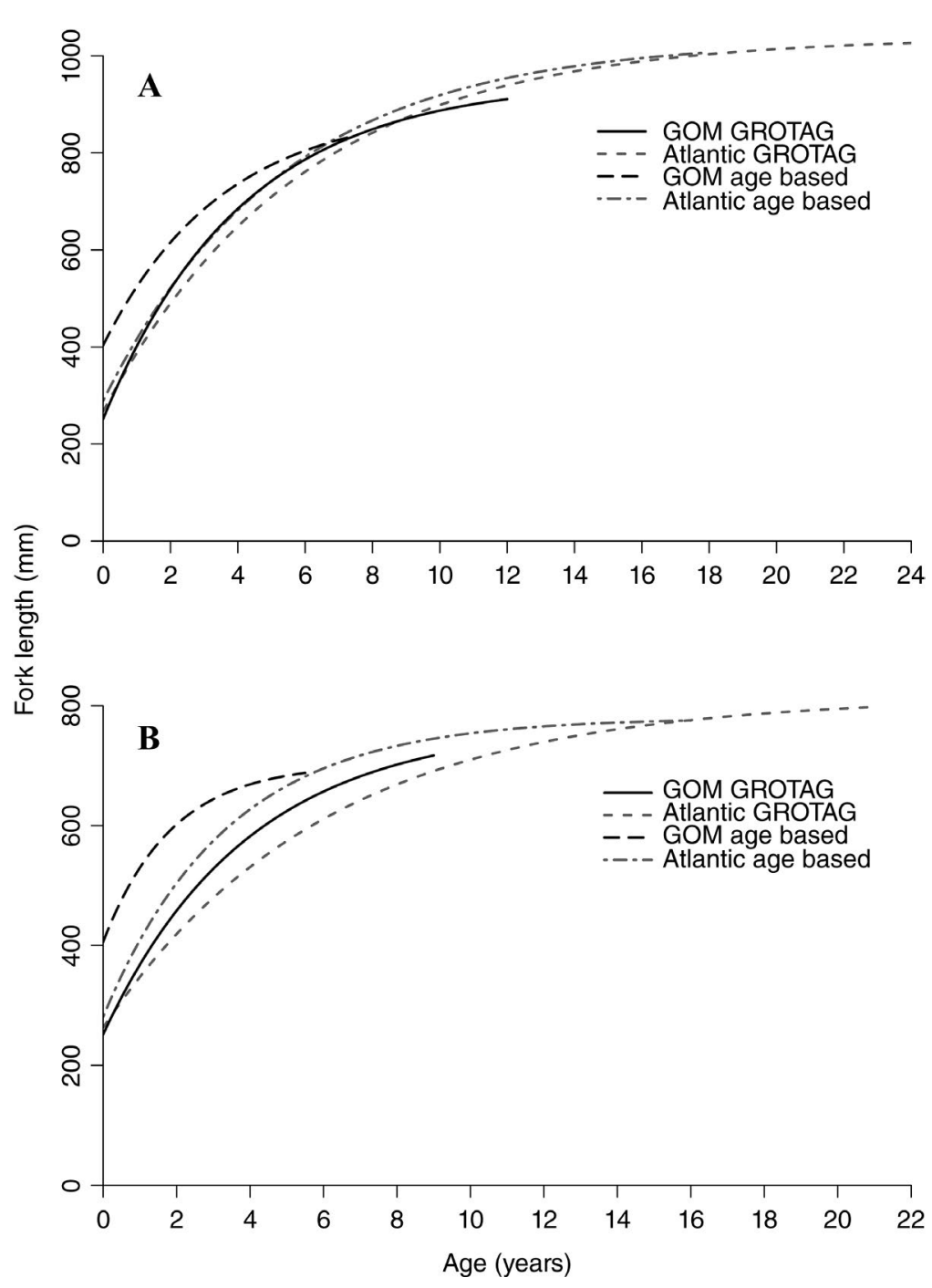

Figure 5

Comparison of growth curves from GROTAG models, which are based on tagrecapture data, and from age-based von Bertalanffy growth functions based on data from Lombardi et al. (2007) and Frazier et al. (2014) for (A) female and (B) male bonnetheads (Sphyrna tiburo) tagged in the northeastern Gulf of Mexico (GOM) during 1993-2006 and off the Atlantic coast of the southeastern United States (Atlantic) during 1998-2019. Age-based models were generated by using original length-at-age data from Lombardi et al. (2007) for sharks in the GOM because published models used total length and band count. model for females in the GOM may be an artifact of sample size, although the model produced much greater variation in growth estimates at $\mathrm{g}_{830}$, contrary to the estimates from other models indicating a source of variation other than sample size. These results indicate that there may be significant underestimation of ages of bonnetheads in the GOM with the age-based models.

Sampling, fishing pressure, or gear bias could have affected results of the age-based models; however, estimates of age at $50 \%$ maturity calculated by using age-independent, length-based growth estimates also point to significant differences in maturity. These estimates of age at $50 \%$ maturity indicate that female bonnetheads mature at an average of 1.5 years and males mature at an average of 3.2 years later than females and males do according to age-based estimates, providing further evidence of age underestimation in the GOM data set. The GROTAG model does not produce comparable estimates of average age at length; however, data from long-term tag-recapture studies were available. When these data were combined with results from growth models, calculated longevity for female and male bonnetheads in the GOM are 8.9 and 11.4 years from the GROTAG models and 6.5 and 10.8 years from the age-based models; these ages are considerably older than the maximum age estimates of $5.5+$ and $7.5+$ reported by Lombardi-Carlson et al. (2003).

Data from long-term tag-recapture efforts and longevity estimates calculated from GROTAG models confirm the report of age underestimation for bonnetheads in the Atlantic region by Frazier et al. (2014). However, for females, length-based estimates of age at $50 \%$ maturity are not significantly different from age-based estimates. If age underestimation was common in the age-based study for sharks in the Atlantic region, it and faster rates at which $k$ is reached compared with estimates from age-based models. Plots of bootstrapped growth estimates for females from the GOM age-based model indicate large uncertainty in growth estimates at the upper reference length. Comparatively, results from GROTAG models for bonnetheads in the Atlantic region and in the GOM and from the age-based model for bonnetheads in the Atlantic region indicate less uncertainty at the upper reference length compared with the lower reference length at which growth is expected to be more variable (Erzini, 1994). The large uncertainty in the age-based may be rare or only in individuals at or near $L_{\infty}$ given the agreement between growth models and life history parameters for females.

Although age and growth studies are not necessarily expected to encounter the oldest individuals in a population because of their relative scarcity (Bishop et al., 2006), there is increasing evidence that age is frequently underestimated in many studies of age and growth of elasmobranch species, especially in those of long-lived species (e.g., Kalish and Johnston, 2001; Francis et al., 2007; Frazier et al., 2015; Harry, 2018; Natanson et al., 2018b). 


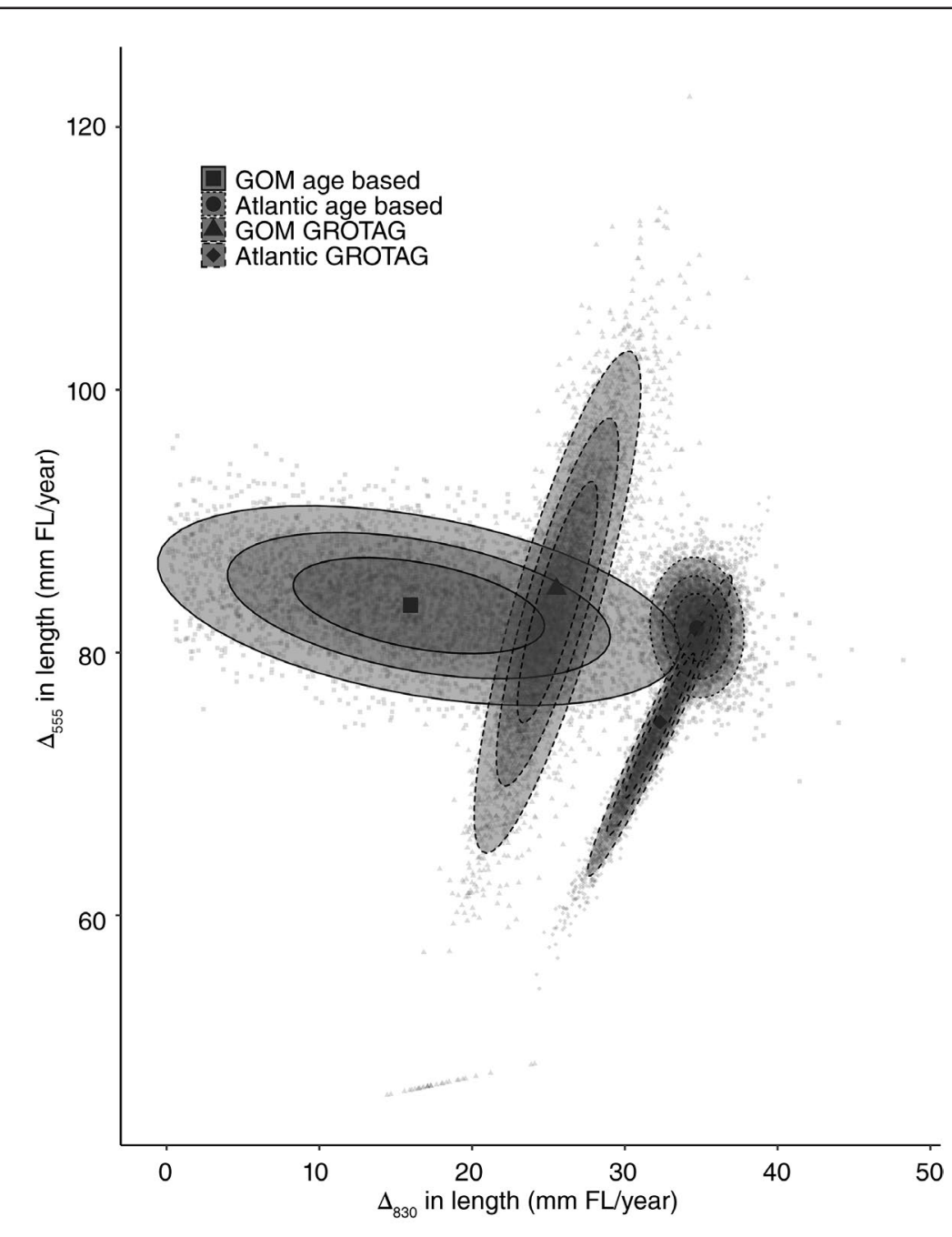

Figure 6

Plot of bootstrap estimates of growth rates $(g)$ at the 2 reference lengths of 555 and $830 \mathrm{~mm}$ fork length (FL), parameters $g_{555}$ and $g_{830}$, from GROTAG models based on tag-recapture data for female bonnetheads (Sphyrna tiburo) tagged in the northeastern Gulf of Mexico (GOM) during 1993-2006 and off the Atlantic coast of the southeastern United States (Atlantic region) during 1998-2019 and from region-specific, age-based von Bertalanffy growth func(2007) for sharks in the GOM and from Frazier et al. (2014) for sharks in the Atlantic region. Mean growth rates for age-based models were calculated from bootstrapped estimates of lengths at ages $\Phi, \mathrm{X}$, and $\Psi$ (parameters $l_{\Phi}, l_{\mathrm{X}}, l_{\Psi}$ ). Estimates are shown with $50 \%, 80 \%$, and $95 \%$ polygon ellipsoid confidence intervals. Bootstrapping was done with 5000 iterations. tions generated by using original length-at-age data from Lombardi et al.

more reliable, estimates of longevity and age-independent estimates of maturity. Although methods of modeling growth with tag-recapture data have historically been considered inferior to age-based methods (Harry, 2018), given recent doubts about the suitability of vertebrae for aging, methods based on tag-recapture data may be more reliable than age-based methods (Harry, 2018; Natanson and Deacy, 2019). When possible, more computationally advanced methods, such as those of Aires-da-Silva et al. (2015) and Francis et al. (2016), which incorporate all available growth data (length based, tag and recapture, and age based) that can be integrated directly into stock assessment models, should be considered because they can combine all available data sources to estimate growth characteristics of a population. Additionally, methods that involve tag-recapture data may be useful in providing growth information for species that are difficult to age and for populations for which sacrifice of specimens is not preferred or fishery-dependent catch are not available for sampling (e.g., for protected species).

Given the large discrepancies between the age-based model and the model based on tag-recapture data for bonnetheads in the GOM, the length-based tag-recapture estimates generated in our study (especially age at $50 \%$ maturity and longevity) likely more accurately describe growth of bonnetheads in the GOM than age-based estimates. Parameters of the VBGF are commonly used in modeling estimates of mortality, maturity, and longevity and in modeling for stock assessments. Use of current age-based parameters for the population in the GOM should be carefully considered until growth in the population can be reexamined. Using parameters that underestimate age and maturity can lead to overly optimistic estimates of growth and mortality rates, increasing the potential for overexploitation of stocks. Results of this study indi-

Results of recent studies indicate that in some species of sharks, band-pair formation may be a function of growth and body girth, not age (Natanson et al., 2018b). The results of our study indicate that the use of tag-recapture methods can produce estimates of growth that are similar to those produced with age-based methods.

When sufficient tag-recapture data are available, models should be used to verify growth estimates from agebased models and provide independent, and perhaps cate that bonnetheads in the GOM may be more susceptible to overexploitation than previously believed. The status of the stocks of bonnetheads in the northeastern GOM and off the Atlantic coast of the southeastern United States are currently considered to be unknown, and no stock assessments are pending. Given these results, we recommend that region-specific assessments be conducted and that they incorporate these new age-independent estimates of life history characteristics. 


\section{Acknowledgments}

We thank G. Ulrich, J. Morris, C. Manire, A. Galloway, and the numerous interns whose countless hours of sampling made this study possible. We also thank L. Natanson, R. Francis, J. Sulikowski, C. Simpfendorfer, J. Ballenger, and L. Lombardi-Carlson for sharing data and providing guidance and input. This research was enabled by NOAA funding to Mote Marine Laboratory, the NOAA COASTSPAN and GULFSPAN surveys, the U.S. Environmental Protection Agency, and the Florida Department of Environmental Protection. This paper is contribution 830 of the South Carolina Marine Resources Center.

\section{Literature cited}

Aires-da-Silva, A. M., M. N. Maunder, K. M. Schaefer, and D. W. Fuller.

2015. Improved growth estimates from integrated analysis of direct ageing and tag-recapture data: an illustration with bigeye tuna (Thunnus obesus) of the eastern Pacific Ocean with implications for management. Fish. Res. 163:119-126. Crossref

Ardizzone, D., G. M. Cailliet, L. J. Natanson, A. H. Andrews,

L. A. Kerr, and T. A. Brown.

2006. Application of bomb radiocarbon chronologies to shortfin mako (Isurus oxyrinchus) age validation. Environ. Biol. Fish. 77:355-366. Crossref

Beamish, R. J., and G. A. McFarlane.

1983. The forgotten requirement for age validation in fisheries biology. Trans. Am. Fish. Soc. 112:735-743. Crossref

Bethea, D. M., L. Hale, J. K. Carlson, E. Cortés, C. A. Manire, and

J. Gelsleichter.

2007. Geographic and ontogenetic variation in the diet and daily ration of the bonnethead shark, Sphyrna tiburo, from the eastern Gulf of Mexico. Mar. Biol. 152:1009-1020. Crossref

Bethea, D. M., M. J. Ajemian, J. K. Carlson, E. R. Hoffmayer,

J. L. Imhoff, R. D. Grubbs, C. T. Peterson, and G. H. Burgess. 2015. Distribution and community structure of coastal sharks in the northeastern Gulf of Mexico. Environ. Biol. Fish. 98:1233-1254. Crossref

Beverton, R. J. H., and S. J. Holt.

1957. On the dynamics of exploited fish populations. Fish. Invest. Ser. 2, vol. 19, 533 p. HMSO, London.

Bishop, S. D. H., M. P. Francis, C. Duffy, and J. C. Montgomery. 2006. Age, growth, maturity, longevity and natural mortality of the shortfin mako shark (Isurus oxyrinchus) in New Zealand waters. Mar. Freshw. Res. 57:143-154. Crossref

Cailliet, G. M., and K. J. Goldman.

2004. Age determination and validation in chondrichthyan fishes. In Biology of sharks and their relatives (J. C. Carrier, J. A. Musick, and M. R. Heithaus, eds.), p. 399-447. CRC Press, Boca Raton, FL.

Cailliet, G. M., H. F. Mollet, G. G. Pittenger, D. Bedford, and

L. J. Natanson.

1992. Growth and demography of the Pacific angel shark (Squatina californica), based upon tag returns off California. Mar. Freshw. Res. 43:1313-1330. Crossref

Cailliet, G. M., W. D. Smith, H. F. Mollet, and K. J. Goldman.

2006. Age and growth of chondrichthyan fishes: the need for consistency in terminology, verification, validation, and growth function fitting. Environ. Biol. Fish. 77:211228. Crossref

Campana, S. E.

2001. Accuracy, precision and quality control in age determination, including a review of the use and abuse of age validation methods. J. Fish Biol. 59:197-242. Crossref

Campana, S. E., L. J. Natanson, and S. Myklevoll.

2002. Bomb dating and age determination of large pelagic sharks. Can. J. Fish. Aquat. Sci. 59:450-455. Crossref

Carlson, J. K., and G. R. Parsons.

1997. Age and growth of the bonnethead shark, Sphyrna tiburo, from northwest Florida with comments on clinal variation. Environ. Biol. Fish. 50:331-341. Crossref

1999. Seasonal differences in routine oxygen consumption rates of the bonnethead shark. J. Fish Biol. 55:876-879. Crossref

Carlson, J. K., and I. E. Baremore.

2003. Changes in biological parameters of Atlantic sharpnose shark Rhizoprionodon terraenovae in the Gulf of Mexico: evidence for density-dependent growth and maturity? Mar. Freshw. Res. 54:227-234. Crossref

Compagno, L. G. V.

1984. FAO species catalogue. Vol. 4. Sharks of the world. An annotated and illustrated catalogue of shark species known to date. Part 2. Carcharhiniformes. FAO Fish. Synop. 125, p. 251-655. FAO, Rome.

Davenport, S., and J. D. Stevens.

1988. Age and growth of two commercially important sharks (Carcharhinus tilstoni and C. sorrah) from northern Australia. Aust. J. Mar. Freshw. Res. 39:417-433. Crossref

Driggers, W., J. Carlson, B. Cullum, J. Dean, and D. Oakley.

2004. Age and growth of the blacknose shark, Carcharhinus acronotus, in the western North Atlantic Ocean with comments on regional variation in growth rates. Environ. Biol. Fish. 71:171. Crossref

Driggers, W. B., III, B. S. Frazier, D. H. Adams, G. F. Ulrich, C. M. Jones, E. R. Hoffmayer, and M. D. Campbell.

2014. Site fidelity of migratory bonnethead sharks Sphyrna tiburo (L. 1758) to specific estuaries in South Carolina, USA. J. Exp. Mar. Biol. Ecol. 459:61-69. Crossref

Drymon, J. M., W. B. Driggers III, D. Oakley, and G. F. Ulrich. 2006. Investigating life history differences between finetooth sharks, Carcharhinus isodon, in the northern Gulf of Mexico and the western North Atlantic Ocean. Gulf Mex. Sci. 24:2-10. Crossref

Dureuil, M., and B. Worm.

2015. Estimating growth from tagging data: an application to north-east Atlantic tope shark Galeorhinus galeus. J. Fish Biol. 87:1389-1410. Crossref

Erzini, K.

1994. An empirical study of variability in length-at-age of marine fishes. J. Appl. Ichthyol. 10:17-41. Crossref

Escatel-Luna, E., D. H. Adams, M. Uribe-Alcocer, V. Islas-Villanueva, and P. Díaz-Jaimes.

2015. Population genetic structure of the bonnethead shark, Sphyrna tiburo, from the western North Atlantic Ocean based on mtDNA sequences. J. Hered. 106:355-365. Crossref

Eveson, J. P., T. Polacheck, and G. M. Laslett.

2007. Consequences of assuming an incorrect error structure in von Bertalanffy growth models: a simulation study. Can. J. Fish. Aquat. Sci. 64:602-617. Crossref

Fabens, A. J.

1965. Properties and fitting of the von Bertalanffy growth curve. Growth 29:265-289.

Francis, M. P., and R. I. C. C. Francis.

1992. Growth rate estimates of New Zealand rig (Mustelus lenticulatus). Aust. J. Mar. Freshw. Res. 43:1157-1176. Crossref 
Francis, M. P., and K. P. Mulligan.

1998. Age and growth of the New Zealand school shark, Galeorhinus galeus. N. Z. J. Mar. Freshw. Res. 32:427440. Crossref

Francis, M. P., S. E. Campana, and C. M. Jones.

2007. Age under-estimation in New Zealand porbeagle sharks (Lamna nasus): is there an upper limit to ages that can be determined from shark vertebrae? Mar. Freshw. Res. 58:10-23. Crossref

Francis, R. I. C. C

1988a. Are growth parameters estimated from tagging and age-length data comparable? Can. J. Fish. Aquat. Sci. 45:936-942. Crossref

1988b. Maximum likelihood estimation of growth and growth variability from tagging data. N. Z. J. Mar. Freshw. Res. 22:43-51. Crossref

Francis, R. I. C. C., A. M. Aires-da-Silva, M. N. Maunder,

K. M. Schaefer, and D. W. Fuller.

2016. Estimating fish growth for stock assessments using both age-length and tagging-increment data. Fish. Res. 180:113-118. Crossref

Frazier, B. S., W. B. Driggers III, D. H. Adams, C. M. Jones, and J. K. Loefer.

2014. Validated age, growth and maturity of the bonnethead Sphyrna tiburo in the western North Atlantic Ocean. J. Fish Biol. 85:688-712. Crossref

Frazier, B. S., W. B. Driggers III, and G. F. Ulrich.

2015. Longevity of Atlantic sharpnose sharks Rhizoprionodon terraenovae and blacknose sharks Carcharhinus acronotus in the western North Atlantic Ocean based on tag-recapture data and direct age estimates [version 2; peer review: 2 approved]. F1000Research 3:190. Crossref

Goldman, K. J.

2004. Age and growth of elasmobranch fishes. In Elasmobranch fisheries management techniques (J. A. Musick and R. Bonfil, eds.), p. 97-132. Asia Pacific Economic Cooperation, Singapore.

Gruber, S. H.

1982. Role of the lemon shark, Negaprion brevirostris (Poey) as a predator in the tropical marine environment: a multidisciplinary study. Fla. Sci. 45:46-75.

Harry, A. V.

2018. Evidence for systemic age underestimation in shark and ray ageing studies. Fish Fish. 19:185-200. Crossref

Heupel, M. R., C. A. Simpfendorfer, A. B. Collins, and J. P. Tyminski. 2006. Residency and movement patterns of bonnethead sharks, Sphyrna tiburo, in a large Florida estuary. Environ. Biol. Fish. 76:47-67. Crossref

Hoffmayer E. R., G. R. Parsons, and J. Horton.

2006. Seasonal and interannual variation in the energetic condition of adult male Atlantic sharpnose shark Rhizoprionodon terraenovae in the northern Gulf of Mexico. J. Fish Biol. 68:645-653. Crossref

Hueter, R. E., and J. P. Tyminski.

2007. Species-specific distribution and habitat characteristics of shark nurseries in Gulf of Mexico waters off peninsular Florida and Texas. Am. Fish. Soc. Symp. 50:193-223.

Kalish, J., and J. Johnston.

2001. Determination of school shark age based on analysis of radiocarbon in vertebral collagen. In Use of the bomb radiocarbon chronometer to validate fish age (J. M. Kalish, ed.), p. 116-129. Fish. Res. Dev. Corp., Canberra, Australia.

Kelly, G. F., and A. M. Barker.

1963. Estimation of population size and mortality rates from tagged redfish, Sebastes marinus L., at Eastport, Maine. ICNAF Spec. Publ. 4:204-209.
Kimura, D. K.

1980. Likelihood methods for the von Bertalanffy growth curve. Fish. Bull. 77:765-776

Kneebone, J., L. J. Natanson, A. H. Andrews, and W. H. Howell. 2008. Using bomb radiocarbon analyses to validate age and growth estimates for the tiger shark, Galeocerdo cuvier, in the western North Atlantic. Mar. Biol. 154:423-434. Crossref

Jensen, A. C.

1967. Effects of tagging on the growth of cod. Trans. Am. Fish. Soc. 96:37-41. Crossref

Jolivet, A., H. de Pontual, F. Garren, and M. L. Bégout.

2009. Effects of T-bar and DST tagging on survival and growth of European hake. In Tagging and tracking of marine animals with electronic devices (J. L. Nielsen, H. Arrizabalaga, N. Fragoso, A. Hobday, M. Lutcavage, and J. Sibert, eds.) p. 181-193. Springer, Dordrecht, Netherlands.

Kohler, N. E., and P. A. Turner.

2019. Distributions and movements of Atlantic shark species: a 52-year retrospective atlas of mark and recapture data. Mar. Fish. Rev. 81(2):1-93. Crossref

Lombardi-Carlson, L. A., E. Cortés, G. R. Parsons, and C. A. Manire. 2003. Latitudinal variation in life-history traits of bonnethead sharks, Sphyrna tiburo, (Carcharhiniformes, Sphyrnidae), from the eastern Gulf of Mexico. Mar. Freshw. Res. 54:875-883. Crossref

Manire, C. A., and S. H. Gruber.

1991. Effect of M-type dart tags on field growth of juvenile lemon sharks. Trans. Am. Fish. Soc. 120:776-780. Crossref

Meyer, C. G., J. M. O’Malley, Y. P. Papastamatiou, J. J. Dale, M. R. Hutchinson, J. M. Anderson, M. A. Royer, and K. N. Holland. 2014. Growth and maximum size of tiger sharks (Galeocerdo cuvier) in Hawaii. PLoS ONE 9(1):e84799. Crossref

Natanson, L. J., and B. M. Deacy.

2019. Using oxytetracycline validation for confirmation of changes in vertebral band-pair deposition rates with ontogeny in sandbar sharks (Carcharhinus plumbeus) in the western North Atlantic Ocean. Fish. Bull. 117:50-58. Crossref

Natanson, L. J., J. J. Mello, and S. E. Campana.

2002. Validated age and growth of the porbeagle shark (Lamna nasus) in the western North Atlantic Ocean. Fish. Bull. 100:266-278.

Natanson, L. J., A. H. Andrews, M. S. Passerotti, and S. P. Wintner 2018a. History and mystery of age and growth studies in elasmobranchs: common methods and room for improvement. In Shark research: emerging technologies and applications for the field and laboratory (J. C. Carrier, M. R. Heithaus, and C. A. Simpfendorfer, eds.), p. 177-199. CRC Press, Boca Raton, FL.

Natanson, L. J., G. B. Skomal, S. L. Hoffman, M. E. Porter, K. J. Goldman, and S. David.

2018b. Age and growth of sharks: do vertebral band pairs record age? Mar. Freshw. Res. 69:1440-1452. Crossref

Nelson, G. A.

2013. fishmethods: fisheries methods and models in R. R package, vers. 1.4-0. [Available from website, accessed November 2019.]

Ogle, D. H.

2012. FSA: fisheries stock analysis. $\mathrm{R}$ package, vers. 0.3.2. [Available from website, accessed November 2019.]

Oliveira, P. G. V.

2001. Levantamento da fauna de elasmobranquios e estudo da biologia comportamental do tubarao limao, Negaprion brevirostris (Poey, 1868), tubarao lixa, Ginglymostoma cirratum (Bonnaterre, 1788) na Reserva Biologica do Atol das Rocas, RN-Brasil. M.S. thesis, 114 p. Univ. Fed. Pernambuco, Recife, Brasil. [In Portuguese.] 
Parsons, G. R.

1987. Life history and bioenergetics of the bonnethead shark, Sphyrna tiburo (Linnaeus): a comparison of two populations. Ph.D. diss., 167 p. Univ. S. Fla., Tampa, FL.

1993. Age determination and growth of the bonnethead shark Sphyrna tiburo: a comparison of two populations. Mar. Biol. 117:23-31. Crossref

Passerotti, M. S., A. H. Andrews, J. K. Carlson, S. P. Wintner, K. J. Goldman, and L. J. Natanson.

2014. Maximum age and missing time in the vertebrae of sand tiger shark (Carcharhinus taurus): validated lifespan from bomb radiocarbon dating in the western North Atlantic and southwestern Indian Oceans. Mar. Freshw. Res. 65:674-687. Crossref

Pistevos, J. C. A., I. Nagelkerken, T. Rossi, M. Olmos, and

S. D. Connell.

2015. Ocean acidification and global warming impair shark hunting behaviour and growth. Sci. Rep. 5:16293. Crossref

Portnoy, D. S., J. B. Puritz, C. M. Hollenbeck, J. Gelsleichter,

D. Chapman, and J. R. Gold.

2015. Selection and sex-biased dispersal in a coastal shark: the influence of philopatry on adaptive variation. Mol. Ecol. 24:5877-5885. Crossref

$\mathrm{R}$ Core Team.

2019. R: a language and environment for statistical computing. $\mathrm{R}$ Foundation for Statistical Computing, Vienna, Austria. [Available from website, accessed November 2019.]

Ricker, W. E.

1975. Computation and interpretation of biological statistics of fish populations. Bull. Fish. Res. Board Can. 191, 333 p.

Rigby, C. L., B. B. Wedding, S. Grauf, and C. A. Simpfendorfer.

2014. The utility of near infrared spectroscopy for age estimation of deepwater sharks. Deep-Sea Res. Oceanogr., 1 94:184-194. Crossref

Saunders, R. L., and K. R. Allen.

1967. Effects of tagging and fin-clipping on the survival and growth of Atlantic salmon between smolt and adult stages. J. Fish. Res. Board Can. 24:2595-2611. Crossref

Scheirer, J. W., and D. W. Coble.

1991. Effects of Floy FD-67 anchor tags on growth and condition of northern pike. North Am. J. Fish. Manage. 11:369-373. Crossref
SEDAR (Southeast Data Assessment and Review).

2013. SEDAR 34 stock assessment report: HMS bonnethead shark, 217 p. SEDAR, North Charleston, SC. [Available from website.]

Simpfendorfer, C. A.

2000. Growth rates of juvenile dusky sharks, Carcharhinus obscurus (Lesueur, 1818), from southwestern Australia estimated from tag-recapture data. Fish. Bull. 98:811-822.

Skomal, G., and D. Bernal.

2010. Physiological responses to stress in sharks. In Sharks and their relatives II: biodiversity, adaptive physiology, and conservation (J. C. Carrier, J. A. Musick, and M. R. Heithaus, eds.), p. 459-490. CRC Press, Boca Raton, FL.

Treble, M. A., S. E. Campana, R. J. Wastle, C. M. Jones, and J. Boje. 2008. Growth analysis and age validation of a deepwater Arctic fish, the Greenland halibut (Reinhardtius hippoglossoides). Can. J. Fish. Aquat. Sci. 65:1047-1059. Crossref

Ulrich, G. F., C. M. Jones, W. B. Driggers III, J. M. Drymon, D. Oakley, and C. Riley.

2007. Habitat utilization, relative abundance, and seasonality of sharks in the estuarine and nearshore waters of South Carolina. Am. Fish. Soc. Symp. 50:125-139.

Vinyard, E. A., B. S. Frazier, J. M. Drymon, J. J. Gelsleichter, and W. J. Bubley.

2019. Age, growth, and maturation of the finetooth shark, Carcharhinus isodon, in the Western North Atlantic Ocean. Environ. Biol. Fish. 102:1499-1517. Crossref

von Bertalanffy, L.

1938. A quantitative theory of organic growth (inquiries on growth laws. II). Hum. Biol. 10:181-213.

Vucic-Pestic, O., R. B. Ehnes, B. C. Rall, and U. Brose.

2011. Warming up the system: higher predator feeding rates but lower energetic efficiencies. Global Chang. Biol. 17:1301-1310. Crossref

Welsford, D. C., and J. M. Lyle.

2005. Estimates of growth and comparisons of growth rates determined from length- and age-based models for populations of purple wrasse (Notolabrus fucicola). Fish. Bull. 103:697-711. 